\title{
Association between somatic cell count during the first lactation and the cumulative milk yield of cows in Irish dairy herds
}

\author{
S. C. Archer, ${ }^{11}$ F. Mc Coy, $†$ W. Wapenaar, ${ }^{*}$ and M. J. Green ${ }^{\star}$ \\ *University of Nottingham, School of Veterinary Medicine and Science, Sutton Bonington Campus, Sutton Bonington, Leicestershire, LE12 5RD, \\ United Kingdom \\ †Animal and Grassland Research and Innovation Centre, Teagasc, Moorepark, Fermoy, Co. Cork, Ireland
}

\section{ABSTRACT}

Reduced potential milk yield is an important component of mastitis costs in dairy cows. The first aim of this study was to assess associations between somatic cell count (SCC) during the first lactation, and cumulative milk yield over the first lactation and subsequent lifetime of cows in Irish dairy herds. The second aim was to assess the association between SCC at 5 to 30 $\mathrm{d}$ in milk during parity 1 (SCC1), and SCC over the entire first lactation for cows in Irish dairy herds. The data set studied included records from 51,483 cows in 5,900 herds. Somatic cell count throughout the first lactation was summarized using the geometric mean and variance of SCC. Data were analyzed using linear models that included random effects to account for the lack of independence between observations, and herdlevel variation in coefficients. Models were developed in a Bayesian framework and parameters were estimated from 10,000 Markov chain Monte Carlo simulations. The final models were a good fit to the data. A 1-unit increase in mean natural logarithm SCC over the first lactation was associated with a median decrease in first lactation and lifetime milk yield of 135 and $1,663 \mathrm{~kg}$, respectively. A 1-unit increase in the variance of natural logarithm SCC over the first lactation was associated with a median decrease in lifetime milk yield of $719 \mathrm{~kg}$. To demonstrate the context of lifetime milk yield results, microsimulation was used to model the trajectory of individual cows and evaluate the expected outcomes for particular changes in herd-level geometric mean SCC over the first lactation. A $75 \%$ certainty of savings of at least $€ 199 /$ heifer in the herd was detected if herd-level geometric mean SCC over the first lactation was reduced from $\geq 120,000$ to $\leq 72,000$ cells $/ \mathrm{mL}$. The association between SCC1 and SCC over the remainder of the first lactation was highly herd dependent, indicating that control measures for heifer mastitis should

Received June 19, 2013.

Accepted December 4, 2013.

${ }^{1}$ Corresponding author: simon.archer@nottingham.ac.uk be preferentially targeted on an individual-herd basis toward either the pre- and peripartum period, or the lactating period, to optimize the lifetime milk yield of dairy cows.

Key words: dairy heifer, somatic cell count, cumulative milk yield

\section{INTRODUCTION}

Increased SCC between 5 and 30 DIM during parity 1 (SCC1) has been reported to have a negative effect on both cumulative milk yield and risk of disposal for cows in Irish dairy herds (Archer et al., 2013a,b). Early-lactation SCC in heifers is considered a reflection of the adequacy of control measures during the pre- and peripartum (ppp) period (De Vliegher et al., 2012), and improving management for ppp heifers to reduce the prevalence of cows with SCC1 $\geq 400,000$ cells $/ \mathrm{mL}$ would be expected to have an economically important impact on lifetime milk yield (LiMY; Archer et al., 2013a). In Belgian and Dutch heifers, increased SCC early in the first lactation has been associated with increased SCC at subsequent test days throughout the first lactation (De Vliegher et al., 2004; SantmanBerends et al., 2012). For cows that survive, SCC beyond early lactation, therefore, gives information on the legacy of IMI from the ppp period, as well as IMI originating while heifers are in milk. A negative relationship between geometric mean first-lactation SCC and cumulative first-lactation milk yield (FLMY) has been reported (Raubertas and Shook, 1982; Hortet and Seegers, 1998). However, to our knowledge, no studies have investigated the association between numeric summaries of SCC throughout the entire first lactation and cumulative milk yield beyond the first lactation. Furthermore, the association between SCC1 and SCC throughout the entire first lactation has not been investigated for cows in Irish dairy herds. These relationships will help understand the relative importance of the ppp and lactating period for the control of heifer mastitis.

The aims of this study were 2-fold: first, to investigate associations between SCC throughout the first lactation and cumulative milk yield over the first lactation 
and the subsequent lifetime of cows in Irish dairy herds. Microsimulation was then used to show the financial impact of herd-level reductions in the prevalence of cows with high SCC during the first lactation in terms of LiMY. The second aim was to assess the association between SCC at 5 to 30 DIM during the first lactation and SCC throughout the entire first lactation of cows in Irish dairy herds.

\section{MATERIALS AND METHODS}

\section{Data Selection}

Data were provided by the Irish Cattle Breeding Federation (Bandon, Co. Cork, Ireland), and 51,483 cows in 5,900 herds were selected. Selection criteria were $\geq 2$ SCC recordings during parity 1 (the first at 5 to 30 DIM between January 2005 and March 2007), and age at first calving (AFC) $\geq 700 \mathrm{~d}$ (to remove $6 \%$ of heifers with increased risk of culling due to dystocia; Berry and Cromie, 2009). The median number of heifers included per herd was 7 (range of 1 to 98). Cumulative milk yields for all lactations up to July 25, 2012, were calculated using a recognized method (Olori et al., 1999). Lactation milk yields were summed for each cow to give an estimate of LiMY from the date of first calving to the end of the study period. Descriptive statistics were calculated for cows in a subset of 5,413 herds (with $\geq 2$ eligible cows/herd) that was split into quartiles based on herd-level geometric mean first-lactation SCC (herd_gSCC_p1; quartile 1: $<72,000$ cells/mL; quartile 2: 72,000 to 93,000 cells/mL; quartile 3: 94,000 to 119,000 cells $/ \mathrm{mL}$; quartile $4: \geq 120,000$ cells $/ \mathrm{mL}$ ). Descriptive statistics included number of cows, firstlactation SCC parameters, proportion of cows with SCC1 $\geq 400,000$ cells/mL, number of recordings in the first lactation, proportion of cows surviving up to the fourth lactation, and first-lactation and LiMY.

\section{First-Lactation SCC and Cumulative Milk Yield}

Statistical Analysis. First-lactation SCC was summarized by its geometric mean and variance, which were positively associated. For comparison, the outcomes of interest $\left(y_{\mathrm{ij}}\right)$ were (1) FLMY or (2) LiMY for the ith cow in the jth herd. Random effects models were developed that took the form

$$
\begin{gathered}
\mathrm{y}_{\mathrm{ij}}=\alpha+\mathbf{X}_{\mathrm{ij}} \boldsymbol{\beta}_{1}+\mathbf{X}_{\mathrm{j}} \boldsymbol{\beta}_{2}+\mathrm{u}_{\mathrm{j}}+\mathrm{e}_{\mathrm{ij}}, \\
\mathrm{u}_{\mathrm{j}} \sim \operatorname{Normal}\left(0, \sigma_{\mathrm{u}}^{2}\right) \\
\mathrm{e}_{\mathrm{ij}} \sim \operatorname{Normal}\left(0, \sigma_{\mathrm{e}}^{2}\right)
\end{gathered}
$$

where $\alpha=$ intercept value, $\mathbf{X}_{\mathbf{i j}}=$ matrix of exposure variables for each cow, $\boldsymbol{\beta}_{1}=$ vector of coefficients for $\mathbf{X}_{\mathbf{i j}}, \mathbf{X}_{\mathbf{j}}=$ matrix of exposure variables for each herd, $\boldsymbol{\beta}_{\mathbf{2}}$ $=$ vector of coefficients for $\mathbf{X}_{\mathbf{j}}, \mathbf{u}_{\mathbf{j}}=$ a random effect to account for residual variation between herds (assumed to be normally distributed, with mean $=0$ and variance $=\sigma_{\mathrm{u}}^{2}$ ), and $\mathrm{e}_{\mathrm{ij}}=$ residual level 1 error (assumed to be normally distributed, with mean $=0$ and variance $=$ $\sigma_{\mathrm{e}}^{2}$ ). The geometric mean and variance of first-lactation SCC, SCC1, and AFC were investigated for inclusion as polynomial terms (to powers of 5) on a natural logarithmic scale to account for nonlinear associations with cumulative milk yield. Month and year of first calving were investigated for inclusion as linear or categorical terms. Biologically plausible interactions and herd-level random slopes (herd $\times$ fixed effect interactions) were assessed. To facilitate posterior predictions from the models that incorporated all uncertainty in parameters, the models for FLMY and LiMY were developed in a Bayesian framework using WinBUGS 1.4.3 software (Lunn et al., 2000). This approach required initial values for covariates to run a Markov chain Monte Carlo (MCMC) procedure and these were generated in MLwiN software (Rasbash et al., 2012), using the iterative generalized least squares procedure (Goldstein, 2003). Parameters were estimated from 10,000 MCMC simulations, following a burn-in of 1,000 simulations, during which time chain convergence occurred, determined by visual inspection of 3 chains to ensure that a stationary distribution had been reached (Gilks et al., 1996). Vague prior distributions were used for the random effect variances $\sigma_{\mathrm{u}}^{-2} \sim$ Gamma $(0.001,0.001), \sigma_{\mathrm{e}}^{-2} \sim$ Gamma $(0.001,0.001)$, and $\boldsymbol{\beta} \sim$ Normal $\left(0,10^{6}\right)$, to give major influence to the data in the estimation of parameters (Green et al., 2004). Distributions of covariates and interaction terms were inspected; these remained in the model based on biological plausibility and if the 95\% Bayesian credible interval (BCI) excluded 0. Sensitivity of the results to prior distributions for the herdlevel random effect variance (Spiegelhalter et al., 2004) was evaluated by repeating simulations using the prior $\sigma_{\mathrm{u}}^{2} \sim$ Uniform $\left(10^{-9}, 10^{9}\right)$.

Model Checking. Fixed and random effects were used to predict cow FLMY and LiMY (y.pred ${ }_{\mathrm{ij}}$ ); thus,

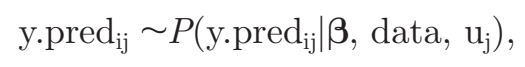

where $y \cdot \operatorname{pred}_{\mathrm{ij}}$ are posterior predictions of cumulative milk yield for the ith cow in the jth herd, $\boldsymbol{\beta}$ is the vector of model coefficient distributions, and $u_{\mathrm{j}}$ is the random effect for the jth herd. Predicted and observed mean FLMY and LiMY were calculated at the cow level for quartiles of cows categorized by geometric mean of first-lactation SCC (quartile 1: $<55,000$ cells/ 
$\mathrm{mL}$; quartile 2: 55,000 to 90,000 cells $/ \mathrm{mL}$; quartile 3: 91,000 to 149,000 cells/mL; quartile $4: \geq 150,000$ cells/ $\mathrm{mL}$ ), or grouped by SCC1 (group 1: $<55,000$ cells $/ \mathrm{mL}$; group 2: 55,000 to 149,000 cells/mL; group 3: 150,000 to 399,000 cells $/ \mathrm{mL}$; group $4: \geq 400,000$ cells $/ \mathrm{mL}$ ); these categories were not in the final models. Posterior predicted distributions of mean cumulative milk yield for cows in these groups were inspected to determine if the observed values were within the $95 \%$ BCI of the posterior predictions, as an indication of internal model fit and usefulness (Gelman et al., 1996).

Microsimulation. Management changes to improve mastitis have an effect on the whole herd rather than individual cows. Therefore, to illustrate the potential effect of reductions in herd_gSCC_p1 on the mean LiMY of cows, and to demonstrate financial relevance, microsimulation was carried out as was conducted in previous research to investigate herd-level reductions in the prevalence of cows with high SCC1 (Archer et al., 2013a). The Bayesian model was, therefore, extended to include a one-step microsimulation of LiMY for 1,000 simulated cows with different characteristics, based on herd_gSCC_p1 quartile. Increase in the mean and variance of natural logarithm of SCC for firstlactation cows by herd was associated with increase in the between-herd variance of these parameters. For each simulated cow, values for the mean and variance of natural logarithm of SCC over the first lactation were, therefore, drawn from normal distributions based on the observed data to give a realistic distribution of values. To demonstrate the effect of an achievable reduction in herd_gSCC_p1 on LiMY, herds with herd_gSCC_p1 in quartile 4 were assumed to move to quartiles 1 or 2 , and herds in quartile 3 were assumed to move to quartile 1 . For ease of comparison, all simulated cows were assumed to have a first-calving date in February 2007. At each of 10,000 MCMC simulations (following a burn-in of 1,000), final model coefficients were combined with data from the simulated cows to generate predictions of LiMY for the ith cow in the jth herd $\left(y \cdot \operatorname{pred}_{i j}\right)$ :

$$
\mathrm{y} \cdot \operatorname{pred}_{\mathrm{ij}} \sim P\left(\mathrm{y} \cdot \operatorname{pred}_{\mathrm{ij}} \mid \boldsymbol{\beta}, \mathrm{X}^{\mathrm{sim}}\right),
$$

where $\boldsymbol{\beta}$ is a vector of model coefficient distributions and $X^{\text {sim }}$ is a matrix of data for simulated cows, including simulated values for the mean and variance of the natural logarithm of SCC over the first lactation, based on herd_gSCC_p1 quartile, and indicator variables to denote a first calving in February 2007.

The mean LiMY for simulated cows in each herd scenario was calculated following each MCMC simulation. Differences in mean LiMY were multiplied by an estimated gross margin (milk price - variable costs of production), that was drawn from a normal distribu- tion with mean $=0.17 € / \mathrm{L}$, and standard deviation $=0.03 € / \mathrm{L}$ for each cow (Hennessy et al., 2011), to give the difference in expected revenue associated with reductions in herd_gSCC_p1. Posterior distributions of mean savings / heifer calved into the herd were plotted as a cumulative probability distribution to show the probability of different levels of financial return for changes in herd_gSCC_p1.

\section{SCC Legacy During the First Lactation: Statistical Analysis}

Proportions of cows in each SCC1 group and firstlactation geometric mean quartile were determined. Mean and variance of the natural logarithm of SCC during the first lactation $\left(\operatorname{Resp}_{\mathrm{ijk}}\right)$ were outcomes in the following bivariate linear model (Rasbash et al., 2012):

$$
\begin{aligned}
& \operatorname{Resp}_{\mathrm{ijk}}=\left(\beta_{0}+\mathrm{v}_{0 \mathrm{k}}+\mathrm{u}_{0 \mathrm{jk}}\right) \cdot \mathrm{z}_{0 \mathrm{jk}}+\left(\beta_{1}+\mathrm{v}_{1 \mathrm{k}}+\mathrm{u}_{1 \mathrm{jk}}\right) \mathrm{z}_{1 \mathrm{jk}} \\
& +\left(\boldsymbol{\beta}_{2}+\mathrm{v}_{2 \mathrm{k}}\right) \cdot \mathrm{z}_{0 \mathrm{jk} .} \mathbf{X}_{\mathrm{jk}}+\left(\boldsymbol{\beta}_{\mathbf{3}}+\mathrm{v}_{3 \mathrm{k}}\right) \cdot \mathrm{z}_{1 \mathrm{jk}} \cdot \mathbf{X}_{\mathrm{jk}} ; \\
& {\left[\begin{array}{c}
\mathrm{v}_{0 \mathrm{k}} \\
\mathrm{v}_{1 \mathrm{k}} \\
\mathrm{v}_{2 \mathrm{k}} \\
\mathrm{v}_{3 \mathrm{k}}
\end{array}\right] \sim \text { Normal }\left(0, \sum_{\mathrm{v}}\right), \sum_{\mathrm{v}}=\left[\begin{array}{llll}
\sigma_{\mathrm{v} 0}^{2} & & & \\
\sigma_{\mathrm{v} 01}^{2} & \sigma_{\mathrm{v} 1}^{2} & & \\
\sigma_{\mathrm{v} 011}^{2} & \sigma_{\mathrm{v} 12}^{2} & \sigma_{\mathrm{v} 2}^{2} & \\
\sigma_{\mathrm{v} 01112}^{2} & \sigma_{\mathrm{v} 122}^{2} & \sigma_{\mathrm{v} 23}^{2} & \sigma_{\mathrm{v} 3}^{2}
\end{array}\right] \text {, }} \\
& {\left[\begin{array}{c}
\mathrm{u}_{0 \mathrm{jk}} \\
\mathrm{u}_{1 \mathrm{jk}}
\end{array}\right] \sim \operatorname{Normal}\left(0, \sum \mathrm{u}\right), \sum \mathrm{u}=\left[\begin{array}{ll}
\sigma_{\mathrm{u} 0}^{2} & \\
\sigma_{\mathrm{u} 01}^{2} & \sigma_{\mathrm{u} 1}^{2}
\end{array}\right] \text {, }}
\end{aligned}
$$

where $z_{0 j k}$, and $z_{1 j k}$ are indicator variables for mean and variance of the natural logarithm of SCC during the first lactation, respectively, for the jth cow in the kth herd. The model intercepts $\beta_{0}$, and $\beta_{1}$ for the mean and variance of first-lactation natural logarithm of SCC, respectively, were allowed to vary randomly to account for lack of independence between cows $\left(\mathrm{u}_{0 \mathrm{k}}\right.$, and $\left.\mathrm{u}_{1 \mathrm{k}}\right)$ and herds $\left(\mathrm{v}_{0 \mathrm{k}}\right.$, and $\left.\mathrm{v}_{1 \mathrm{k}}\right)$. Exposure variables for each cow (matrix $\mathbf{X}_{\mathbf{j k}}$ ) had corresponding vectors of coefficients $\boldsymbol{\beta}_{2}$ and $\boldsymbol{\beta}_{3}$ for the mean and variance of first-lactation natural logarithm of SCC, respectively, which could vary randomly at the herd level, as defined by $\mathrm{v}_{2 \mathrm{k}}$ and $v_{3 k}$. Cow-level random effects $\left(u_{0 k}\right.$, and $\left.u_{1 k}\right)$ were assumed to have a multivariate normal distribution with mean $=0$ and covariance matrix $=\Sigma_{\mathrm{u}}$, consisting of variances for the mean and variance of natural logarithm of SCC throughout the first lactation: $\sigma_{\mathrm{u} 0}^{2}$ and $\sigma_{\mathrm{u} 1}^{2}$, respectively, and their covariance $\sigma_{\mathrm{u} 01}^{2}$. The herdlevel random effects covariance matrix $\left(\Sigma_{\mathrm{v}}\right)$ had an expanded structure to include variances for random coefficients, in addition to the intercepts, and hence additional covariance terms. The model was fitted using MCMC in MLwiN software (Browne, 2012), with vague 
prior distributions for $\sigma_{\mathrm{vi}}^{-2} \sim$ Gamma $(0.001,0.001), \sigma_{\mathrm{ui}}^{-2}$ $\sim$ Gamma $(0.001,0.001)$, and $\boldsymbol{\beta} \sim$ Normal $\left(0,10^{6}\right)$. Somatic cell count between 5 and 30 DIM during parity 1 was the exposure of interest and this was included as natural logarithm-scale polynomials. In order for the model to be useful for predictions of the mean and variance of first-lactation natural logarithm of SCC by 30 DIM, only confounding variables deemed to be operating by 30 DIM were assessed. These were month of first calving, AFC, and DIM at the first recording. Biologically plausible interactions and herd-level random slopes (for SCC1) were investigated for inclusion. Parameters were included in the model if the 95\% BCI excluded 0 and there was a reduction in the deviance information criteria (Spiegelhalter et al., 2002). Convergence was assessed by inspection of chains to ensure that a stationary distribution had been reached (Browne, 2012), and model fit was assessed by checking distributions of cow and herd-level mean residuals for normality (Goldstein, 2003).

\section{RESULTS}

\section{Descriptive Results}

Lifetime milk yield for all 51,483 cows was evaluated over maximum follow-up times between 5.3 and 7.5 yr. Descriptive statistics, grouped by herd_gSCC_p1 quartile, are shown in Table 1 . Trends were observed for decreased FLMY, LiMY, and proportions of cows surviving with increasing herd_gSCC_p1. These changes were associated with an increase in the herd-level proportion of recordings with high SCC, both at 5 to 30 DIM ( $\geq 400,000$ cells $/ \mathrm{mL}$ ), and throughout the first lactation $(\geq 400,000$ and $\geq 200,000$ cells $/ \mathrm{mL}$ ), and also increased variability in these proportions between herds (Table 1). Increasing herd_gSCC_p1 was associated with increasing variance of the mean natural logarithm of SCC for cows over the first lactation both between and within herds (Table 1). Forty-six percent of cows had $\mathrm{SCC} 1<150,000$ cells $/ \mathrm{mL}$ and geometric mean first-lactation SCC $\leq 90,000$ cells $/ \mathrm{mL}$, and only $5 \%$ of cows had SCC1 $\geq 150,000$ cells/mL and geometric mean first-lactation $\mathrm{SCC} \leq 90,000$ cells $/ \mathrm{mL}$ (Table 2). Twenty-four percent of cows had SCC $1<150,000$ cells/ $\mathrm{mL}$ and geometric mean first-lactation SCC $>90,000$ cells $/ \mathrm{mL}$ (Table 2). Similarly, $25 \%$ of cows had SCC1 $\geq 150,000$ cells $/ \mathrm{mL}$ and geometric mean first-lactation SCC >90,000 cells $/ \mathrm{mL}$ (Table 2 ).

\section{First-Lactation SCC and Cumulative Milk Yield}

Model Results. The final model for FLMY (model 1; Table 3) accounted for month and AFC. Cows that calved in June 2007, aged 27 mo were used as the baseline for comparison. A 1-unit increase in mean natural logarithm of SCC over the first lactation (for example, an increase in first-lactation geometric mean SCC (GMSCC) from 50,000 to 150,000 cells $/ \mathrm{mL}$, or 150,000 to 400,000 cells $/ \mathrm{mL}$ ) was associated with a median decrease in FLMY of $135 \mathrm{~kg}$ (95\% BCI of 108 to $163 \mathrm{~kg}$ ). Variance of natural logarithm of SCC over the first lactation was not associated with change in FLMY. An interaction was observed between natural logarithm of SCC over the first lactation and AFC, and FLMY decreased with decreasing AFC (Figure 1).

The final model for LiMY (model 2; Table 3) accounted for month and year of first calving, and AFC. A 1-unit increase in the mean natural logarithm of SCC over the first lactation was associated with a median decrease in LiMY of $1,663 \mathrm{~kg}$ (95\% BCI of 1,347 to 1,986 $\mathrm{kg}$; calculated by adding the polynomial terms for natural logarithm of SCC over the first lactation from model 2; Table 3). A 1-unit increase in the variance of natural logarithm of SCC over the first lactation was associated with a median decrease in LiMY of $719 \mathrm{~kg}(95 \%$ BCI of 553 to $888 \mathrm{~kg}$ ). In contrast to model 1, decrease in AFC from 27 to 24 mo was associated with a median increase in LiMY of $574 \mathrm{~kg}$ (95\% BCI of 483 to $663 \mathrm{~kg}$ ).

Model Checking. Predictions of FLMY or LiMY for cows aggregated in quartiles by geometric mean first-lactation SCC indicated good fit and, hence, that models 1 and 2 were adequate for predictions in these herds (Figure 2). There was $<1 \%$ difference in the median, and 95\% BCI limits of the coefficient distributions for exposures of interest when a uniform prior distribution for the herd-level random effect variance was used, indicating that choice of prior distribution had no substantive effect on model interpretation.

Microsimulation. Figure 3 shows the cumulative probability distribution of potential cost savings for every heifer in the herd attributable to increased LiMY, associated with reductions in herd_gSCC_p1. Direct probabilities for different levels of saving can be read from Figure 3. For example, there was $75 \%$ certainty of cost savings of at least $€ 199 /$ heifer in the herd if herd_gSCC_p1 decreased from $\geq 120,000$ to $\leq 72,000$ cells $/ \mathrm{mL}$. That would be equivalent to moving from the upper to the lower quartile for herd_gSCC_p1 (Table1). For a herd in which 20 heifers complete the first lactation, this is equivalent to a saving of €3,980 associated with moving from the highest to the lowest herd_gSCC_p1 quartile. Further scenarios for the example herd are given in Table 4.

\section{SCC Legacy During the First Lactation: Model Results}

The association between the natural logarithm of SCC1 and both the mean and variance of the natural 


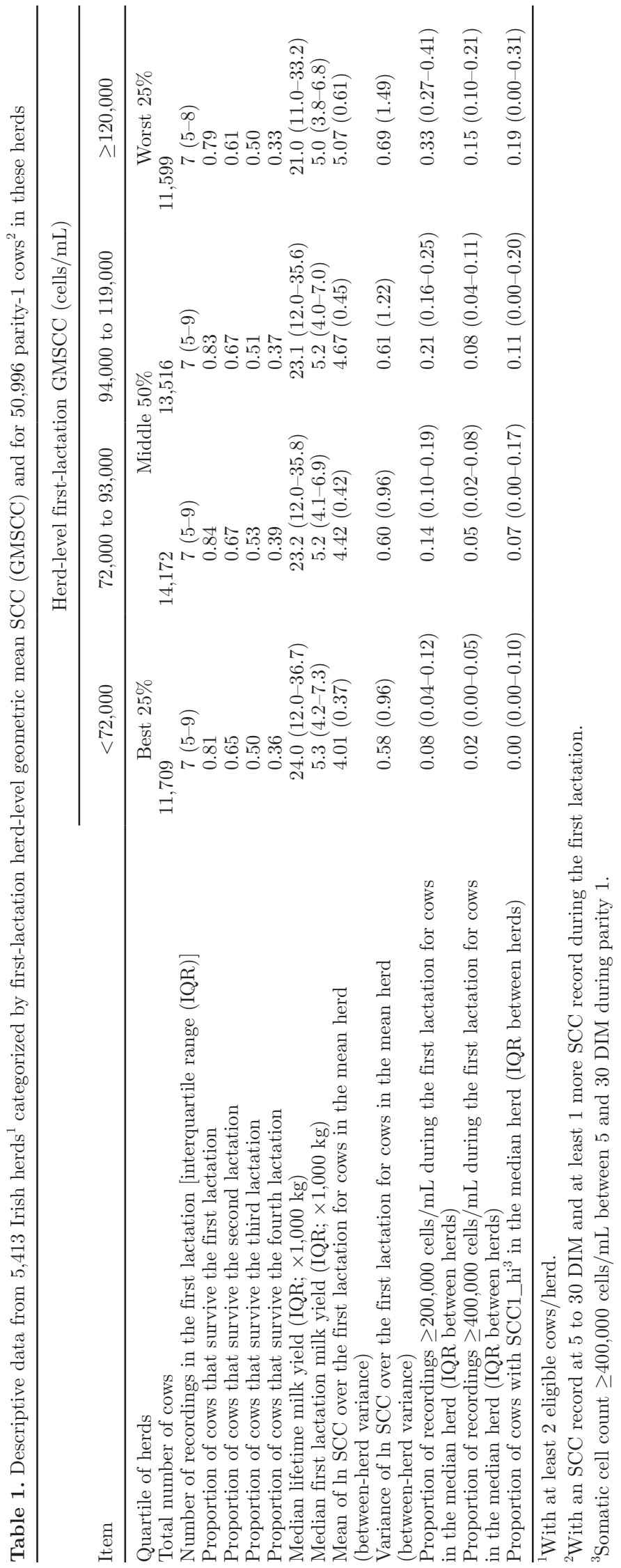

logarithm of SCC throughout the first lactation varied by herd (model 3; Tables 5 and 6 ), and the betweenherd variation in the relationship between SCC1 and GMSCC during the first lactation was large (Table 6; Figure 4). For most herds, an increase in SCC1 was associated with an increase in geometric mean firstlactation SCC, but this was not always the case (Figure 4). The mean (baseline) AFC in model 3 was 27 mo and this interacted with SCC1 (Table 5). With SCC1 unchanged, a 3-mo change in AFC was positively associated with a median change in GMSCC during the first lactation of $1.4 \%$ (95\% BCI of 0.6 to $2.1 \%$ ). The impact of SCC1 on SCC throughout the first lactation increased with time of measurement between 5 and 30 DIM (Table 5; Figure 5).

\section{DISCUSSION}

To our knowledge, this study is the first to demonstrate large differences in cumulative milk yield over the first lactation and subsequent lifetime of cows associated with the geometric mean and variance of SCC during the first lactation. The results highlight that, in addition to the importance of optimizing the udder health of heifers in early lactation (De Vliegher et al., 2005; Archer et al., 2013a), optimal udder health is also vital throughout the remainder of the first lactation in terms of lifetime productivity. The median decrease in LiMY of $1,663 \mathrm{~kg} / 1$-unit increase in mean ln SCC over the first lactation was much larger than the median first-lactation milk loss of $135 \mathrm{~kg}$ associated with a 1-unit increase in mean $\ln$ SCC over the first lactation. Cumulative measures of milk yield depend on both longevity and daily milk yield while alive. Therefore, a greater negative effect of high first-lactation GMSCC on cumulative milk production occurs over a longer time period, as was observed previously for SCC1 (Archer et al., 2013a). In particular, the effect of high first-lactation GMSCC on FLMY relates to when IMI and raised SCC actually occurs. If this is late in the first lactation, the impact on FMLY will be relatively small. In contrast, the potential impact of high first-lactation GMSCC on LiMY is larger, as this is considered over up to $7.5 \mathrm{yr}$. The difference in the time period over which cumulative milk yield is measured is also an explanation for a decrease in LiMY, but not FLMY associated with an increase in the variance of first-lactation SCC, which relates to increased risk of IMI (Schepers et al., 1997).

The first-lactation milk loss we identified was similar to the estimate made by Raubertas and Shook (1982); however, it exceeded estimates from higher-yielding cows in more recent studies based on test-day recordings, in which a 1-unit increase in mean $\ln$ SCC over the first 
Table 2. Proportion of 51,483 Irish dairy cows in each SCC1 group $^{1}$ and cow-level first-lactation geometric mean SCC (GMSCC) quartile

\begin{tabular}{lccccc}
\hline \multirow{2}{*}{$\begin{array}{l}\text { SCC1 group } \\
(\times 1,000 \text { cells } / \mathrm{mL})\end{array}$} & \multicolumn{4}{c}{ First-lactation GMSCC quartile $(\times 1,000$ cells $/ \mathrm{mL})$} & \\
\cline { 2 - 5 } & $<55$ & 55 to 90 & 91 to 149 & $\geq 150$ & \multirow{2}{*}{ Total } \\
\hline$<55$ & 0.15 & 0.09 & 0.04 & 0.01 & 0.29 \\
55 to 149 & 0.07 & 0.15 & 0.13 & 0.06 & 0.41 \\
150 to 399 & 0.01 & 0.03 & 0.06 & 0.08 & 0.18 \\
$\geq 400$ & 0.00 & 0.01 & 0.03 & 0.08 & 0.12 \\
Total & 0.23 & 0.28 & 0.26 & 0.23 & 1.00 \\
\hline
\end{tabular}

${ }^{1}$ Somatic cell count between 5 and 30 DIM during parity 1 .

lactation was associated with losses of 85 to $120 \mathrm{~kg}$ over 305 d for primiparous cows (Dürr et al., 2008; Halasa et al., 2009). Importantly, previous analyses based on test-day recordings only show the milk loss in affected cows that survive, which is probably associated with residual udder pathology, but exclude milk loss associated with premature culling. In contrast, cumulative measures of milk yield take cow longevity into account to give a more realistic estimate of milk loss. The trend for higher FLMY with increased AFC may relate to the size of heifers at calving, which would be expected to increase with AFC, with larger heifers being better able to compete with cows in the herd for resources. This is consistent with previous research (Berry and Cromie, 2009). However, lower AFC appears desirable, as it is associated with increased longevity and, hence, LiMY (Berry and Cromie, 2009; Archer et al., 2013a,b). This is possibly because subsequent lactations more likely fall in line with the seasonal calving patterns of Irish dairy herds (Archer et al., 2013c).

Geometric mean and variance of first-lactation SCC includes SCC1; therefore, losses were higher than previ-

Table 3. Bayesian credible intervals from 10,000 simulations of the final models; outcomes of cow-level first-lactation and lifetime milk yields $(\mathrm{kg})$

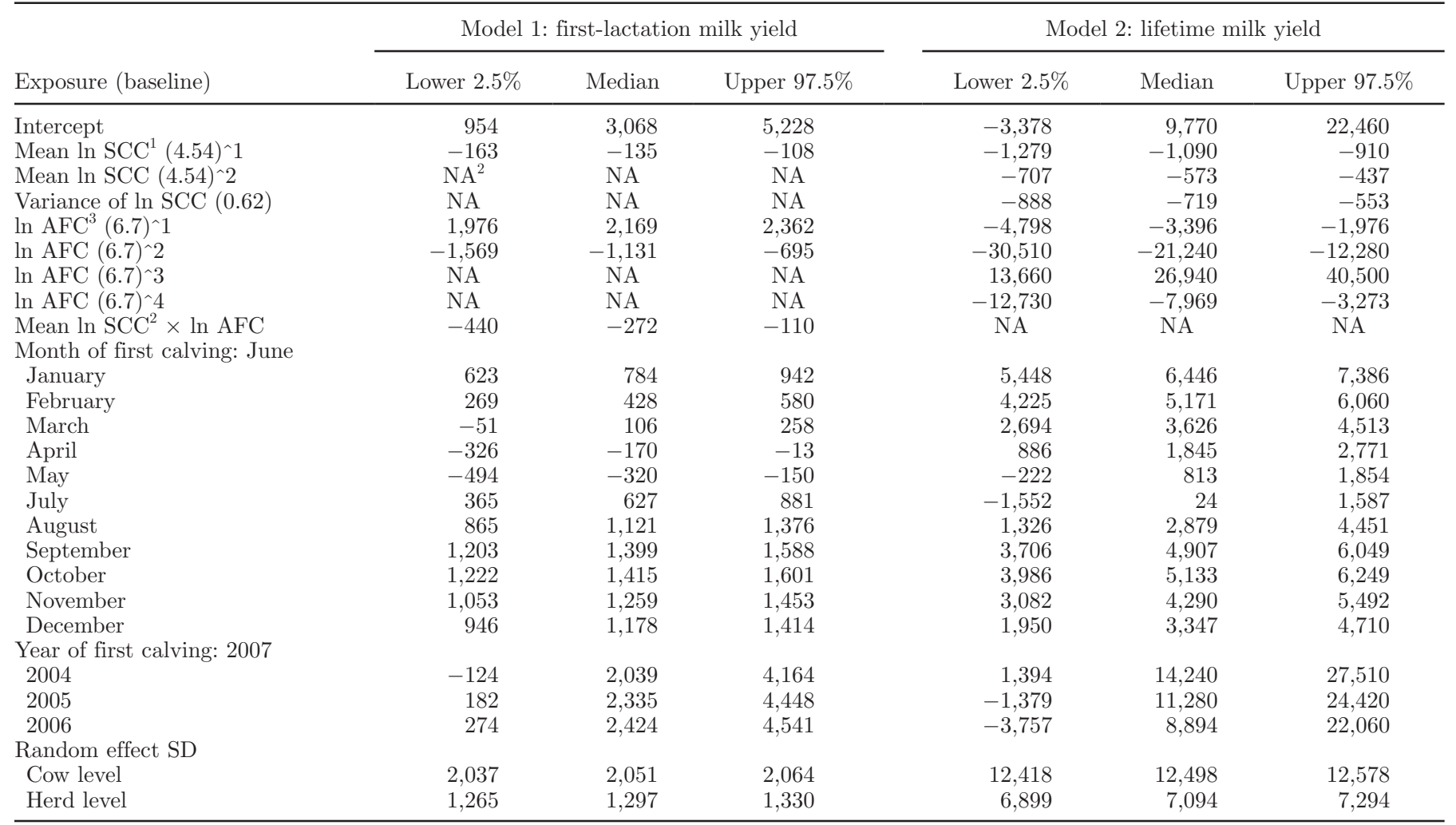

${ }^{1}$ Over the entire first lactation.

${ }^{2} \mathrm{NA}=$ not applicable.

${ }^{3} \mathrm{AFC}=$ age at first calving (d). 


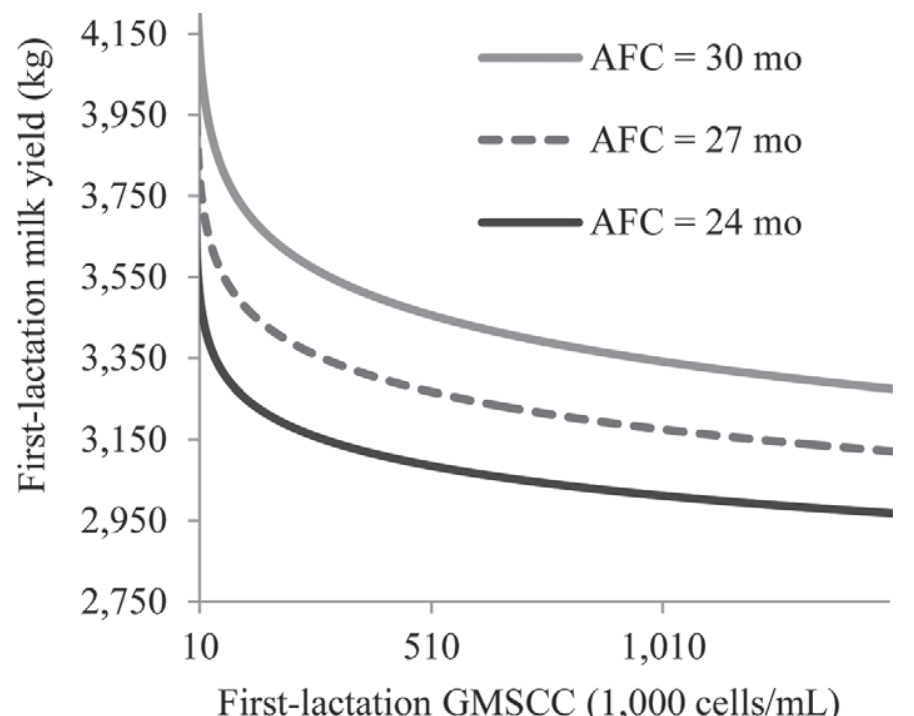

Figure 1. Median predictions of first-lactation milk yield for specific cows (first calving in February 2007) from model 1 (exposure: mean natural logarithm of SCC over the first lactation) to show the effect of age at first calving (AFC). GMSCC = geometric mean SCC.

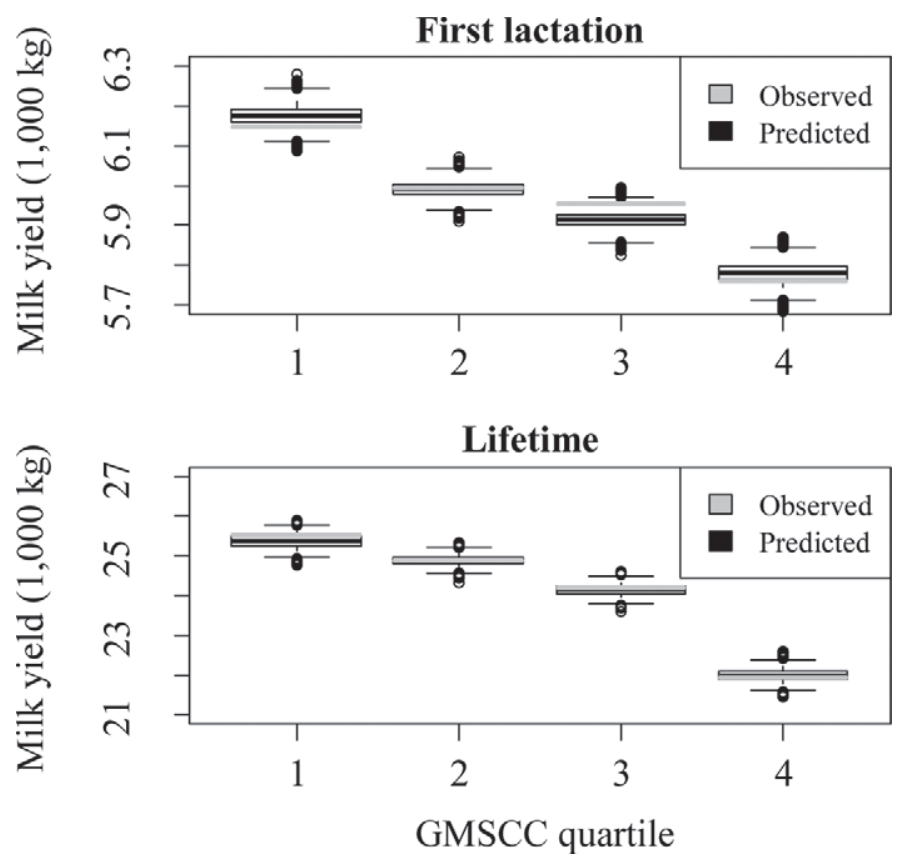

Figure 2. Assessment of model fit and usefulness; predictions of first-lactation and lifetime milk yield from 10,000 simulations of model 1 (exposures: first-lactation mean and variance of natural logarithm of SCC over the first lactation) and model 2 (exposures: first-lactation mean natural logarithm of SCC over the first lactation), respectively, and observed values in 5,900 Irish dairy herds grouped by first-lactation geometric mean SCC (GMSCC; group 1: $<55,000$ cells $/ \mathrm{mL}$; group 2: 55,000 to 89,000 cells/mL; group 3: 90,000 to 149,000 cells/ $\mathrm{mL}$; group 3: $\geq 150,000$ cells $/ \mathrm{mL}$ ). The horizontal line is the median, the surrounding boxes contain $50 \%$ of the data, the vertical whiskers extend to 1.5 times the interquartile range, and outliers are shown beyond this.
Table 4. Simulated cost savings $(€)$ through increased lifetime milk vield $^{1}$ associated with specific reductions in herd-level first-lactation geometric mean SCC (GMSCC), for an example herd in which 20 heifers complete the first lactation

\begin{tabular}{lccc}
\hline & \multicolumn{3}{c}{ Herd-level first-lactation GMSCC $\left(\right.$ quartiles $\left.^{2}\right)$} \\
\cline { 2 - 4 } Probability & 4 to 1 & 4 to 2 & 3 to 1 \\
\hline 0.75 & $\geq 3,980$ & $\geq 3,100$ & $\geq 1,820$ \\
0.5 & $\geq 4,220$ & $\geq 3,260$ & $\geq 2,020$ \\
0.25 & $\geq 4,460$ & $\geq 3,420$ & $\geq 2,200$ \\
\hline
\end{tabular}

${ }^{1}$ Milk margin was drawn from a normal distribution with mean $=0.17$ $€ / L$ and $\mathrm{SD}=0.03 € / \mathrm{L}$ for each cow.

${ }^{2} 1: \leq 72,000$ cells/mL; $2: 72,000$ to 93,000 cells/mL; $3: 93,000$ cells $/ \mathrm{mL}$ to 120,000 cells $/ \mathrm{mL} ; 4: \geq 120,000$ cells $/ \mathrm{mL}$.

ous median estimates for the reduction in FLMY and subsequent LiMY of 105 and $864 \mathrm{~kg}$, respectively, associated with 1-unit increase in ln SCC1 (Archer et al., 2013a), as the time period at risk of IMI is greater. Inclusion of SCC1 and interactions with SCC1 and geometric mean and variance of first-lactation SCC in models 1 and 2 did not improve fit to the data and had no additional effect on FLMY or LiMY, respectively (95\% BCI included 0). This is likely because SCC1 and first-lactation GMSCC are correlated (model 3), and

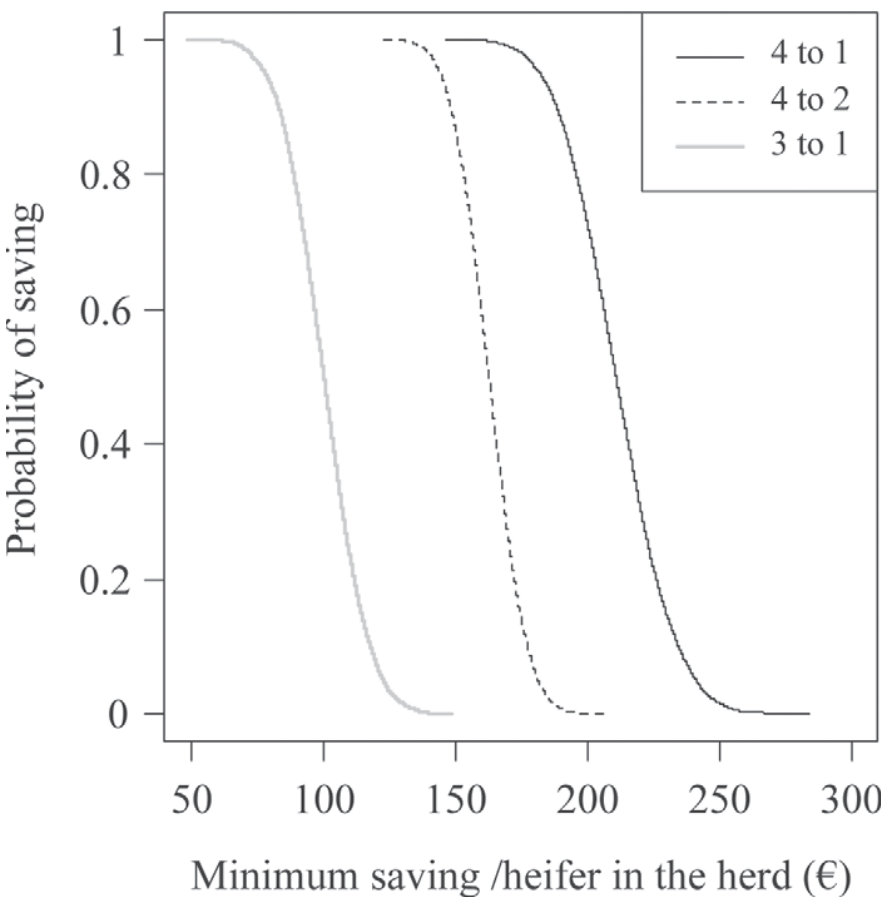

Figure 3. Microsimulation over 10,000 simulations of model 2 (exposures: first-lactation mean and variance of natural logarithm of SCC over the first lactation); minimum cost saving/heifer in the herd attributable to increased lifetime milk yield associated with reduction in herd quartile ( $1: \leq 72,000$ cells $/ \mathrm{mL} ; 2: 72,000$ to 93,000 cells $/ \mathrm{mL} ; 3$ : 93,000 cells $/ \mathrm{mL}$ to 120,000 cells/mL; $4: \geq 120,000$ cells $/ \mathrm{mL}$ ) for firstlactation geometric mean SCC. 
Table 5. Bayesian credible interval for fixed effects following 10,000 simulations of the final model for the mean and variance of natural logarithm of SCC during the first lactation (model 3)

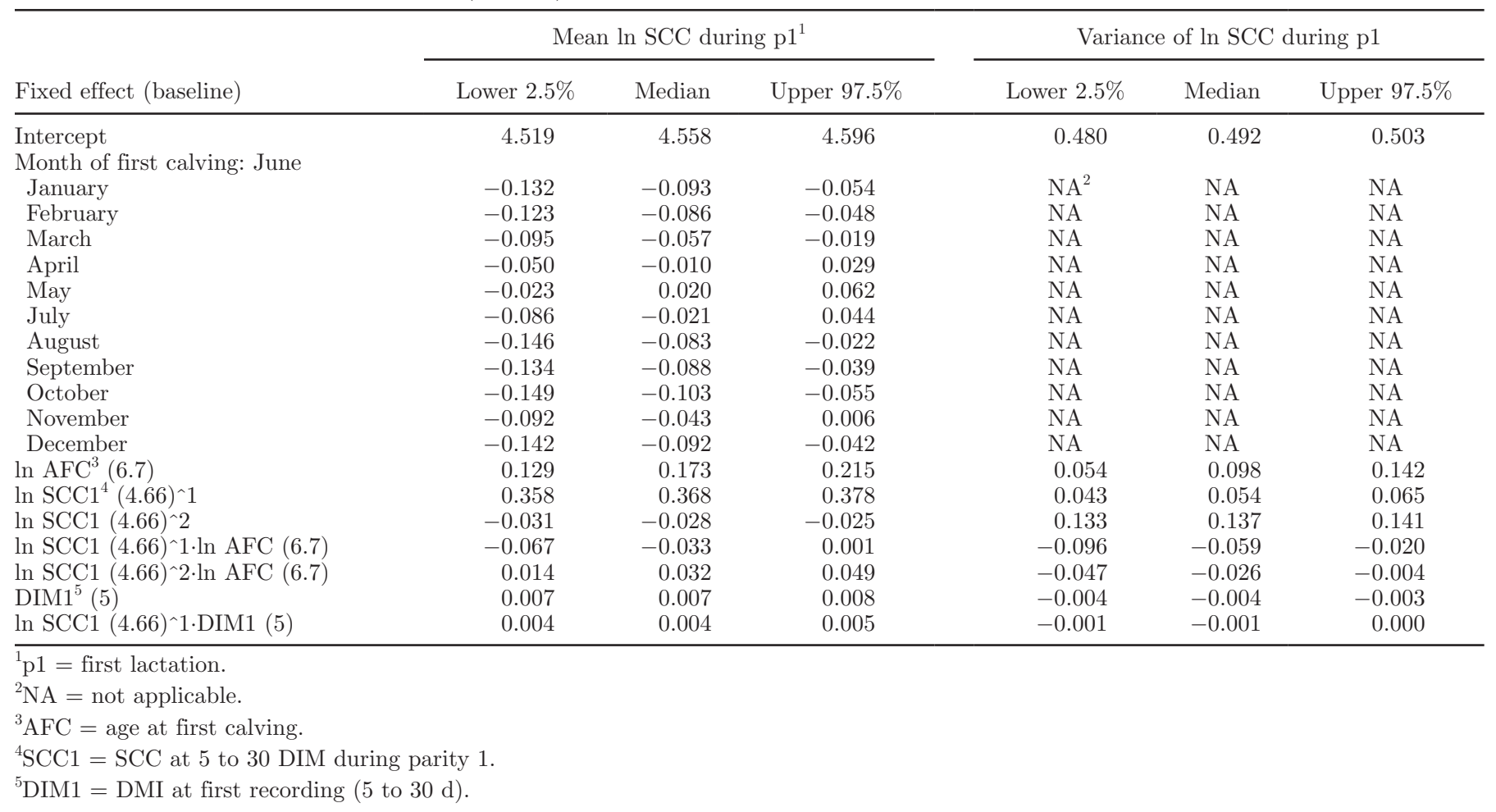

this mediates the impact of SCC1 on cumulative milk yield, as previously reported (De Vliegher et al., 2005). To enable mean and variance of natural logarithm of SCC over the first lactation to be calculated for all heifers, the current study only included data for heifers that survived for at least 2 recordings in the first lactation. Therefore, compared with Archer et al. (2013a), the total impact of mastitis early in the first lactation on cumulative milk yield has probably been underestimated, because cows that were culled soon after calving were excluded. Furthermore, additional economic benefits may exist through mastitis control measures applied during lactation for multiparous cows, if these are housed with heifers.

Heifers with high SCC in early lactation may have high GMSCC throughout the first lactation (De Vliegher et al., 2004; Santman-Berends et al., 2012), as a result of failure to cure from early lactation IMI or subsequent new IMI. In this study, the impact of high SCC1 on SCC throughout the first lactation depended on the magnitude of the increase in SCC1, and when it was measured. This finding is consistent with a higher rate of decrease in SCC after calving for uninfected heifers and those with IMI due to minor pathogens compared with heifers with IMI due to major pathogens or chronic IMI (Barkema et al., 1999). Importantly, the association between cow-level SCC1 and GMSCC over the first lactation in the current study varied between herds (Figure 4), suggesting that differences in the dynamics of IMI and the management of heifers between herds has an important effect on patterns of SCC during the first lactation. This may relate to differences in the detection and treatment of mastitis, infection pressure in the herd from the environment and other cows, parlor management routines that risk transmission of pathogens to uninfected cows, or variability in stress factors such as production level that may impede recovery from IMI. In addition to high cow SCC early in the first lactation (Archer et al., 2013a), high SCC throughout the entire first lactation was associated with reduced FLMY and LiMY. Therefore, control measures to reduce SCC in an individual herd may be relatively more important during either the ppp period (Green et al., 2008) or the lactating period (Barkema et al., 2009). A rational approach to managing heifer mastitis in herds with high first-lactation GMSCC would be to identify if this is a result of high SCC during the ppp or the lactating period and prioritize control measures accordingly, as both scenarios appear equally likely in Irish dairy heifers (Table 2). Further investigations should evaluate risk factors for heifer mastitis in terms of impact on SCC throughout the entire first lactation to develop herd-specific management interventions to optimize the LiMY of dairy cows. 

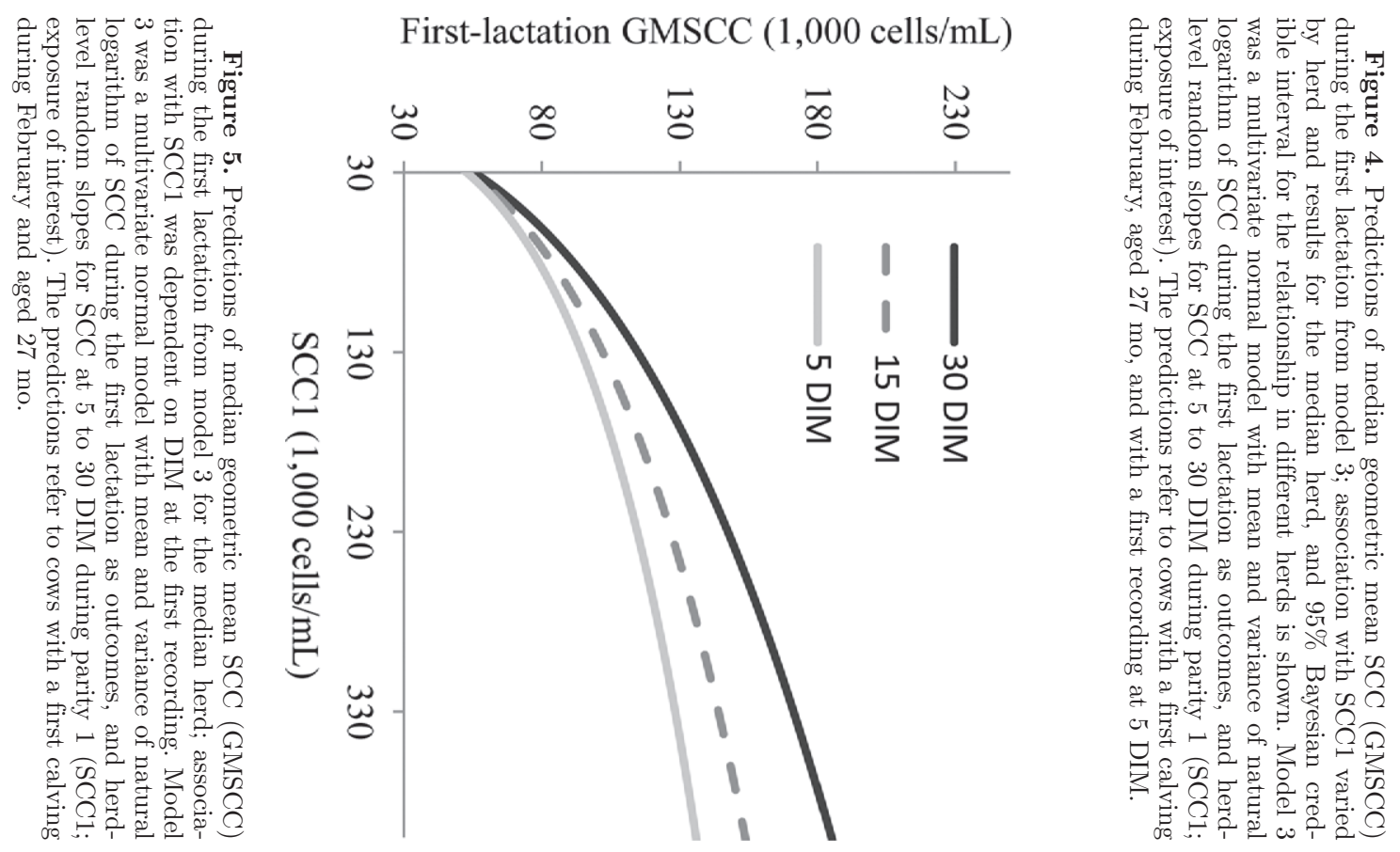

First-lactation GMSCC (1,000 cells/mL)

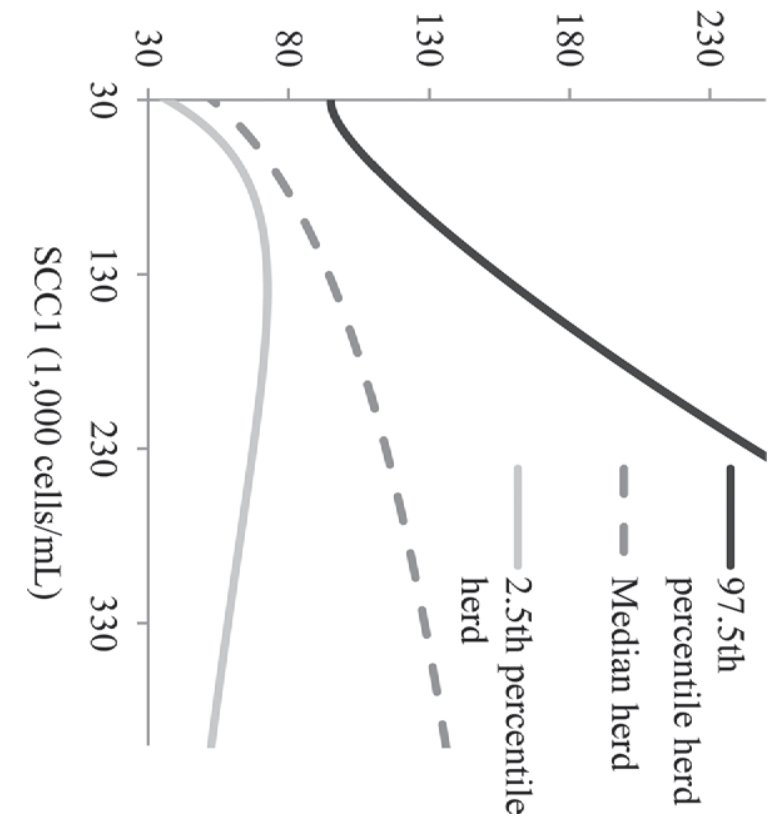

Table 6. Matrices of median (co)variances (95\% Bayesian credible interval) following 10,000 simulations of the final model; outcomes of mean and variance of natural logarithm of SCC during the first lactation (model 3)

\begin{tabular}{|c|c|c|c|c|c|c|c|}
\hline \multicolumn{2}{|c|}{ Cow level } & \multicolumn{6}{|c|}{ Herd level } \\
\hline$\sigma_{\mathrm{u} 0}^{21}$ & $\sigma_{\mathrm{u} 1}^{2}{ }^{2}$ & $\sigma_{\mathrm{v} 0}^{23}$ & $\sigma_{\mathrm{v} 1}^{24}$ & $\sigma_{\mathrm{v} 2}^{25}$ & $\sigma_{\mathrm{v} 3}^{26}$ & $\sigma_{\mathrm{v} 4}^{27}$ & $\sigma_{\mathrm{v} 5}^{28}$ \\
\hline $\begin{array}{l}0.274(0.271 \text { to } 0.278) \\
0.066(0.063 \text { to } 0.069)\end{array}$ & 0.310 (0.306 to 0.314$)$ & $\begin{array}{l}0.049(0.045 \text { to } 0.052) \\
-0.006(-0.009 \text { to }-0.004) \\
0.008(0.006 \text { to } 0.009) \\
-0.001(-0.002 \text { to } 0.000) \\
-0.023(-0.025 \text { to }-0.021) \\
0.001(0.000 \text { to } 0.003)\end{array}$ & $\begin{array}{l}0.031(0.027 \text { to } 0.034) \\
-0.008(-0.010 \text { to }-0.007) \\
0.003(0.002 \text { to } 0.004) \\
0.002(0.000 \text { to } 0.004) \\
-0.004(-0.005 \text { to }-0.003)\end{array}$ & $\begin{array}{l}0.013(0.012 \text { to } 0.015) \\
0.000(0.00 \text { to } 0.001) \\
-0.001(-0.003 \text { to } 0.000) \\
-0.004(-0.005 \text { to }-0.003)\end{array}$ & $\begin{array}{l}0.002(0.002 \text { to } 0.002) \\
-0.002(-0.003 \text { to }-0.002) \\
-0.002(-0.002 \text { to }-0.001)\end{array}$ & $\begin{array}{l}0.019(0.017 \text { to } 0.022) \\
0.000(-0.001 \text { to } 0.001)\end{array}$ & $0.008(0.008$ to 0.009$)$ \\
\hline \multicolumn{8}{|c|}{ 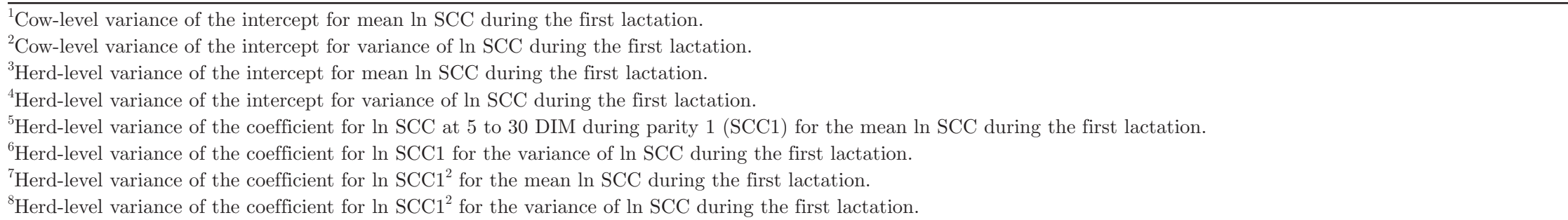 } \\
\hline
\end{tabular}




\section{CONCLUSIONS}

This study demonstrated that for cows in Irish dairy herds, geometric mean and variance of first lactation SCC were negatively associated with both FLMY and LiMY. The apparent legacy of SCC early in the first lactation on SCC for the remainder of the first lactation was highly herd dependent. Approximately 50\% of Irish dairy herds have potential to make savings through reducing SCC throughout the first lactation. This could involve preferentially targeting mastitis control measures in a herd-specific manner toward the ppp period, or toward the lactating period, depending on individual herd SCC patterns. Further research is needed to define the most cost-effective control measures in different circumstances.

\section{ACKNOWLEDGMENTS}

S. C. Archer was funded by a Teagasc Walsh Fellowship (Moorepark, Fermoy, Co. Cork, Ireland). The authors thank the Irish Cattle Breeding Federation (Bandon, Co. Cork, Ireland) for access to their database.

\section{REFERENCES}

Archer, S. C., F. Mc Coy, W. Wapenaar, and M. J. Green. 2013a. Association between somatic cell count early in the first lactation and the lifetime milk yield of cows in Irish dairy herds. J. Dairy Sci. 96:2951-2959.

Archer, S. C., F. Mc Coy, W. Wapenaar, and M. J. Green. 2013b. Association between somatic cell count early in the first lactation and the longevity of Irish dairy cows. J. Dairy Sci. 96:2939-2950.

Archer, S. C., F. Mc Coy, W. Wapenaar, and M. J. Green. 2013c. Association of season and herd size with somatic cell count for cows in Irish, English, and Welsh dairy herds. Vet. J. 196:515-521.

Barkema, H. W., H. A. Deluyker, Y. H. Schukken, and T. J. Lam. 1999. Quarter-milk somatic cell count at calving and at the first six milkings after calving. Prev. Vet. Med. 38:1-9.

Barkema, H. W., M. J. Green, A. J. Bradley, and R. N. Zadoks. 2009. Invited review: The role of contagious disease in udder health. J. Dairy Sci. 92:4717-4729.

Berry, D. P., and A. R. Cromie. 2009. Associations between age at first calving and subsequent performance in Irish spring calving Holstein-Friesian dairy cows. Livest. Sci. 123:44-54.

Browne, W. J. 2012. MCMC Estimation in MLwiN, v2.26. Centre for Multilevel Modelling, University of Bristol, Bristol, UK.

De Vliegher, S., H. W. Barkema, H. Stryhn, G. Opsomer, and A. de Kruif. 2004. Impact of early lactation somatic cell count in heifers on somatic cell counts over the first lactation. J. Dairy Sci. 87:3672-3682.

De Vliegher, S., H. W. Barkema, H. Stryhn, G. Opsomer, and A. de Kruif. 2005. Impact of early lactation somatic cell count in heifers on milk yield over the first lactation. J. Dairy Sci. 88:938-947.
De Vliegher, S., L. K. Fox, S. Piepers, S. McDougall, and H. W. Barkema. 2012. Invited review: Mastitis in dairy heifers: Nature of the disease, potential impact, prevention, and control. J. Dairy Sci. 95:1025-1040.

Dürr, J. W., R. I. Cue, H. G. Monardes, J. Moro-Méndez, and K. M. Wade. 2008. Milk losses associated with somatic cell counts per breed, parity and stage of lactation in Canadian dairy cattle. Livest. Sci. 117:225-232.

Gelman, A., X. Meng, and H. Stern. 1996. Posterior predictive assessment of model fitness via realized discrepancies. Statist. Sinica 6:733-807.

Gilks, W. R., S. Richardson, and D. J. Spiegelhalter. 1996. Markov chain Monte Carlo in practice. Chapman and Hall, London, UK.

Goldstein, H. 2003. Multilevel Statistical Models. 3rd ed. Arnold, London, UK.

Green, M. J., A. J. Bradley, G. F. Medley, and W. J. Browne. 2008. Cow, farm, and herd management factors in the dry period associated with raised somatic cell counts in early lactation. J. Dairy Sci. 91:1403-1415.

Green, M. J., P. R. Burton, L. E. Green, Y. H. Schukken, A. J. Bradley, E. J. Peeler, and G. F. Medley. 2004. The use of Markov chain Monte Carlo for analysis of correlated binary data: Patterns of somatic cells in milk and the risk of clinical mastitis in dairy cows. Prev. Vet. Med. 64:157-174.

Halasa, T., M. Nielen, A. P. W. De Roos, R. Van Hoorne, G. de Jong, T. J. G. M. Lam, T. van Werven, and H. Hogeveen. 2009. Production loss due to new subclinical mastitis in Dutch dairy cows estimated with a test-day model. J. Dairy Sci. 92:599-606.

Hennessy, T., B. Moran, A. Kinsella, and G. Quinlan. 2011. National Farm Survey 2010. Accessed May 18, 2012. http://www.teagasc. ie/publications/2011/1016/NFS10.pdf.

Hortet, P., and H. Seegers. 1998. Calculated milk production losses associated with elevated somatic cell counts in dairy cows: A review and critical discussion. Vet. Res. 29:497-510.

Lunn, D. J., N. Best, and D. Spiegelhalter. 2000. WinBUGS-A Bayesian modelling framework: Concepts, structure, and extensibility. Stat. Comput. 10:325-337.

Olori, V. E., S. Brotherstone, W. G. Hill, and B. J. McGuirk. 1999. Fit of standard models of the lactation curve to weekly records of milk production of cows in a single herd. Livest. Prod. Sci. 58:55-63.

Rasbash, J., F. Steele, W. J. Browne, and H. Goldstein. 2012. A User's Guide to MLwiN, v2.26. Centre for Multilevel Modelling, University of Bristol, Bristol, UK.

Raubertas, R. F., and G. E. Shook. 1982. Relationship between lactation measures of somatic cell concentration and milk yield. J. Dairy Sci. 65:419-425.

Santman-Berends, I. M. G. A., R. G. M. Olde Riekerink, O. C. Sampimon, G. van Schaik, and T. J. G. M. Lam. 2012. Incidence of subclinical mastitis in Dutch dairy heifers in the first 100 days in lactation and associated risk factors. J. Dairy Sci. 95:2476-2484.

Schepers, A. J., T. J. G. M. Lam, Y. H. Schukken, J. B. M. Wilmink, and W. J. A. Hanekamp. 1997. Estimation of variance components for somatic cell counts to determine thresholds for uninfected quarters. J. Dairy Sci. 80:1833-1840.

Spiegelhalter, D. J., K. R. Abrams, and J. P. Myles. 2004. Bayesian approaches to clinical trials and health-care evaluation. Wiley, Chichester, UK.

Spiegelhalter, D. J., N. G. Best, B. P. Carlin, and A. van der Linde. 2002. Bayesian measure of model complexity and fit. J. R. Stat. Soc., B 64:583-639. 